\title{
FIBROBLAST GROWTH REGULATORY FACTOR INHIBITS DNA SYNTHESIS IN BALB/c 3T3 CELLS BY ARRESTING IN G1
}

\author{
PRASANTA DATTA and C. V. NATRAJ \\ Department of Biological Chemistry, The University of Michigan, \\ Ann Arbor, MI 48109, USA
}

\begin{abstract}
SUMMARY
A cell surface macromolecular component from quiescent BALB/c 3T3 mouse cells (designated fibroblast growth regulatory factor, FGRF) inhibits DNA synthesis and cell division in growing 3T3 cells. Addition of FGRF to synchronized populations of growing 3 T3 cells in the late G1 or early S phase did not inhibit DNA synthesis in the immediate S phase. However, a significant inhibition was observed in the $S$ phase of the next round of cell cycle. Cells exposed to the regulatory factor in late S/early G2 or early G1 showed reduced DNA synthesis in the upcoming S phase; the late S/early G2 cells were more sensitive to inhibition than the cells in the G1. Further, the regulatory factor delayed the progression of $\mathrm{GO} / \mathrm{G} 1$-arrested cells into the next $\mathrm{S}$ phase. These results suggest that the physiological effect of FGRF is to arrest cells in early G1, thus preventing their entry into a new round of cell cycle. In contrast to untransformed 3T3 cells, mouse cells transformed by SV40 were not subjected to growth-arrest by the regulatory factor, although the transformed cells contain active FGRF that inhibits DNA synthesis in growing 3T3 cells.
\end{abstract}

Mammalian cells in culture require a complex medium containing small molecular weight nutrients and serum for growth. Depending on the culture condition normal untransformed cells exist in two states, proliferative or quiescent. Growth-arrest of proliferative cells may be brought about by limiting the supply of serum factors and nutrients such as amino acids, glucose, phosphate and vitamins, or by addition of certain drugs, CAMP, and succinylated ConA to the culture medium; when grown to high saturation density, growing cells also become quiescent exhibiting densitydependent inhibition of growth [1-3]. Cells transformed by tumor viruses, on the other hand, exist only in proliferative state, lose their density-dependent inhibition of growth, and continue to grow until the medium is depleted at which time cell death occurs [1-3]. The basic mechanism(s) by which untransformed cells attain quies- cence and continue to remain viable for some time is not known. In a previous report [4] we showed that a loosely attached cell surface component extracted under mild conditions from serum-deprived quiescent BALB/c 3 T 3 mouse cells (designated fibroblast growth regulatory factor, FGRF) inhibited DNA synthesis and cell division in growing $3 \mathrm{~T} 3$ cells. The active FGRF was converted to an inactive form by preincubating in situ intact quiescent cells with uridine diphosphate $N$-acetyl-D-glucosamine (UDP-GlcNAc) which resulted in the glycosylation of some cell surface acceptors [5]. In addition, UDP-GlcNAc-treated cells showed an increased uptake potential of several different classes of nutrients in conditioned medium indicating that restoration of 'underglycosylated' cell surface acceptors with $N$-acetyl-D-glucosamine (GlcNAc) residues led to metabolic stimulation of quiescent cells [5]. Based on these findings 
we proposed [4] that the onset of quiescence of sparse $3 \mathrm{~T} 3$ cells is due to a causal relationship between depletion of growth factors in the culture medium and the presence of active FGRF on the cell surface; further, conversion of active FGRF to an inactive form under favorable nutritional status may be viewed as a switch to allow DNA synthesis and cell division. In this report we provide experimental evidence to suggest that the physiological effect of the FGRF is to arrest cells in early G1, thus preventing DNA synthesis and cell division. We also show that mouse cells transformed by Simian virus-40 (SV-3T3) are not subjected to growth-arrest by the regulatory factor, although the transformed cells contain active FGRF that inhibits DNA synthesis in 3 T 3 cells.

\section{MATERIALS AND METHODS}

\section{Cell culture}

BALB/c 3T3 mouse cells and SV40-transformed (SV3T3) cells were obtained from Dr W. W. Brockman, and were free of mycoplasma as judged by radioautography. Sparse quiescent cultures of 3T3 cells were obtained by seeding $1 \times 10^{5}$ cells in $60 \mathrm{~mm}$ (Lux) dishes in Eagle's modified minimal essential medium with 2 or $4 \%$ calf serum (GIBCO) and incubating them at $37^{\circ} \mathrm{C}$ for $72-96 \mathrm{~h}$ in a humidified $\mathrm{CO}_{2}$ incubator without medium change, at which time $40-50 \%$ confluency was obtained [5]. In some experiments, $1 \times 10^{5}$ cells were grown in $2 \%$ serum for $48 \mathrm{~h}$ and incubated for a period of $12 \mathrm{~h}$ in serum-free medium containing $250 \mu \mathrm{g} / \mathrm{ml}$ of crystalline bovine serum albumin to achieve quiescence. Cells arrested in early S phase by hydroxyurea were obtained by a modified procedure of Tobey \& Crissman [6] as follows: serum-depleted quiescent cells $\left(2-3 \times 10^{5}\right.$ cells $/ 60 \mathrm{~mm}$ dish) were exposed to 1 $\mathrm{mM}$ hydroxyurea in complete medium with $10 \%$ serum and incubated for $24 \mathrm{~h}$ at $37^{\circ} \mathrm{C}$ in a $\mathrm{CO}_{2}$ incubator; to release the hydroxyurea block, cells were washed with warm phosphate-buffered saline (PBS), and allowed to grow in complete medium with $10 \%$ serum and supplements as indicated. Mitotic cells were obtained by seeding $2 \times 10^{6}$ cells in $150 \mathrm{~mm}$ dishes. After a growth period of $48 \mathrm{~h}$ in $10 \%$ serum, the cells were treated with $0.08 \mu \mathrm{g} / \mathrm{ml}$ of colcemid (Sigma) for $2 \mathrm{~h}$ and manually shaken to detach cells in mitosis. The cells were collected by centrifugation, washed in warm PBS and replated in complete medium with $10 \%$ serum and other supplements as described. Cell number was determined by a Coulter counter after detaching them from the culture dishes with trypsin in divalent cationfree PBS containing $0.02 \%$ EDTA [5].

\section{Extraction of FGRF}

The active regulatory factor from quiescent $3 \mathrm{~T} 3$ cells was extracted by incubating PBS-washed cells in serum-free medium containing $0.2 \mathrm{M}$ urea as described [4]. The extract was dialysed, lyophilized and dissolved in sterile PBS. The inactive FGRF was isolated from UDP-GIcNAc-treated quiescent cells [5] in a manner identical with that described above. To obtain regulatory factor from SV-3T3 cells, $1 \times 10^{5}$ cells were seeded in complete medium with $4 \%$ serum and grown for $72 \mathrm{~h}$ without medium change. The medium was then replaced with serum-free medium containing 250 $\mu \mathrm{g} / \mathrm{ml}$ of crystalline bovine serum albumin, and the culture incubated for $12 \mathrm{~h}$ at $37^{\circ} \mathrm{C}$ in a $\mathrm{CO}_{2}$ incubator. The medium was removed and the cells, washed with PBS, were extracted with urea solution as described. For a comparable extract from 3T3 cells, an identical protocol was used for culture of cells and extraction of FGRF.

\section{DNA synthesis}

The number of cells actively synthesizing DNA was determined by autoradiography of labeled nuclei. The concentration of $\left[{ }^{3} \mathrm{H}\right]$ thymidine (New England $\mathrm{Nu}$ clear) and the time of exposure are given with each experiment. In general, the cells were grown on coverslips (two $22 \mathrm{~mm}$ square coverslips $/ 60 \mathrm{~mm}$ dish). After treatment with $\left[{ }^{3} \mathrm{H}\right]$ thymidine the cells were washed in divalent cation-free PBS, and fixed with ethanol-acetic acid $(3: 1 \mathrm{vol} / \mathrm{vol})$. The coverslips were washed with $70 \%$ ethanol, dried, mounted on glass slides and coated with NTB-2 Kodak Nuclear Track emulsion. After appropriate time of exposure, the emulsion was developed and the number of nuclei labeled as well as the total number of cells were counted. The data are expressed as percent nuclei labeled (labeling index); the values are averages of $400-500$ cells counted from two coverslips from each dish in duplicates.

\section{Mitotic index}

To determine the percentage of cells in mitosis (mitotic index), cells were swelled in $0.56 \% \mathrm{KCl}$, fixed in methanol-acetic acid $(3: 1 \mathrm{vol} / \mathrm{vol})$ and stained with Giemsa stain.

\section{RESULTS}

\section{Response of Gl cells to FGRF}

When quiescent $3 \mathrm{~T} 3$ cells, arrested primarily in the G0/G1 stage by serum limitation, are stimulated with serum, synthesis of DNA resumes after a lag period. In den- 


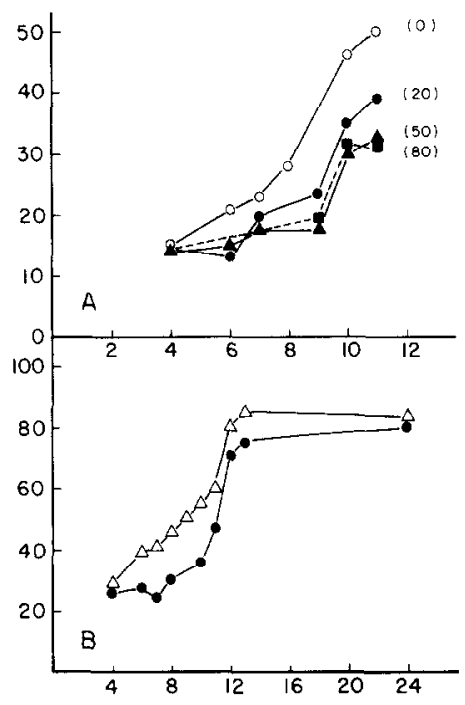

Fig. 1. Abscissa: time (hours); ordinate: nuclei labeling index $(\%)$.

Kinetics of nuclei labeling $(A)$ as a function of concentrations of extract from quiescent $3 \mathrm{~T} 3$ cells $(\mu \mathrm{g}$ protein $/ \mathrm{ml}$ as indicated next to each curve); $(B)$ with extracts $(20 \mu \mathrm{g}$ protein $/ \mathrm{ml})$ from quiescent cells (-) or from UDP-GlcNAc-treated restored cells $(\triangle-\triangle)$. Cells $\left(1 \times 10^{5} / 60 \mathrm{~mm}\right.$ dish $)$ were seeded in $4 \%$ serum and grown for $72 \mathrm{~h}$ to achieve quiescence. At zero time, the medium was replaced with complete medium containing $10 \%$ serum, $\left[{ }^{3} \mathrm{H}\right]$ thymidine $(1 \mu \mathrm{Ci} / \mathrm{ml})$ and various extracts. Cells were fixed for autoradiography at the times specified.

sity-inhibited quiescent cells the lag period is approx. 12-14 h [1-3]. However, cells plated in low serum concentration reach quiescence in sparse culture density as judged by low uptake rates of various metabolites, reduced rate of DNA synthesis (less than $10 \%$ of that seen in growing cells) as well as no increase in cell number upon further incubation (cf ref. [5]). Upon serum addition, these cells begin DNA synthesis in 4-6 $\mathrm{h}$ and the nuclei labeling index reaches a maximum value in $12-16 \mathrm{~h}$; a representative experiment is illustrated in fig. 1. It would appear that, under these conditions, these cells are presumably arrested in $\mathrm{G} 1$ and not in a 'G0 loop'.

The effect of various concentrations of active FGRF on the kinetics of nuclei label-

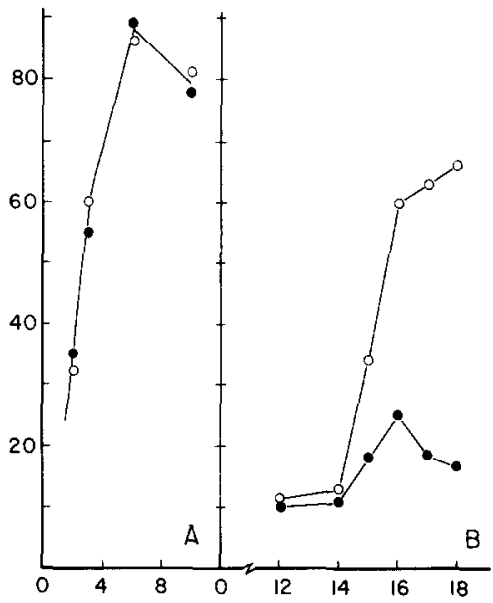

Fig. 2. Abscissa: time (hours); ordinate: nuclei labeling index $(\%)$.

Kinetics of nuclei labeling after release of hydroxyurea-arrested cells in $10 \%$ serum with (-O) and without $(\mathrm{O}-\mathrm{O})$ extract $(20 \mu \mathrm{g}$ protein $/ \mathrm{ml})$ from quiescent cells. Cells $\left(2-3 \times 10^{5} / 60 \mathrm{~mm}\right.$ dish $)$ were treated with hydroxyurea, washed with warm PBS and incubated in complete medium with $10 \%$ serum with or without extract. To separate sets of dishes $\left[{ }^{3} \mathrm{H}\right]$ thymidine $(1 \mu \mathrm{Ci} / \mathrm{ml})$ was added $(A)$ at zero time; $(B)$ at $11 \mathrm{~h}$. Cells were fixed for autoradiography at times indicated after release of hydroxyurea block.

ing after addition of serum to sparse quiescent $3 \mathrm{~T} 3$ cells is shown in fig. $1 \mathrm{~A}$. At 20 $\mu \mathrm{g}$ of protein/ml there was a significant delay in the onset of DNA synthesis as compared with a control culture without FGRF; a maximum delay of about $3 \mathrm{~h}$ is seen at higher concentrations of the factor. Interestingly, in all cases the slopes of the curves following the lag periods were approximately the same, indicating that addition of FGRF only delayed their entry into the $\mathrm{S}$ phase, and that at the end of the extended G1 period the cells exposed to FGRF were able to synthesize DNA almost at the same rate as that of a control culture (cf fig. $1 B$ ).

The experiments depicted in fig. $1 B$ compare the labeling kinetics of cells treated with the active FGRF from quiescent cells and the inactive factor isolated from 're- 


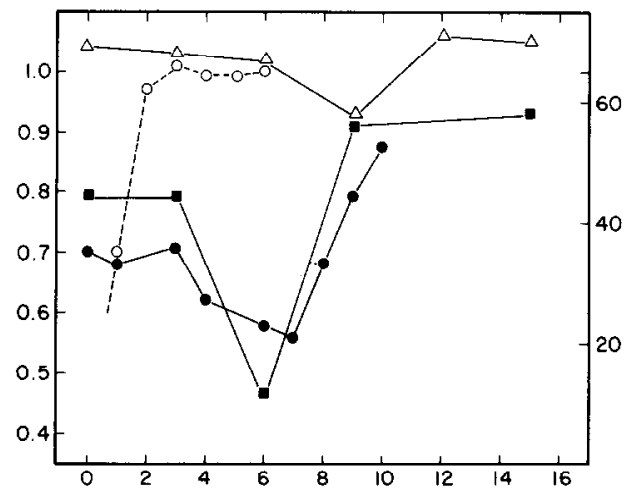

Fig. 3. Abscissa: time (hours); ordinate: (left) rel. labeling index (defined by the ratio of labeling index with extract over the labeling index in PBS control); (right) nuclei labeling index (\%).

Extent of nuclei labeling as a function of incubation time with extracts $(20 \mu \mathrm{g}$ protein $/ \mathrm{ml})$ from quiescent cells (-O, - $\mathbf{-}$ ) and UDP-GlcNAc-treated restored cells $(\triangle-\Delta)$. Cells $\left(2 \times 10^{5} / 60 \mathrm{~mm}\right.$ dish) were treated with hydroxyurea, washed with warm PBS and incubated in complete medium with $10 \%$ serum. Extracts or PBS were added to separate dishes at times indicated. At $12 \mathrm{~h}$ after release of hydroxyurea block, $\left[{ }^{3} \mathrm{H}\right]$ thymidine $(1 \mu \mathrm{Ci} / \mathrm{ml})$ was added to each dish, and cells were fixed for autoradiography after an additional $18 \mathrm{~h}$ incubation period. The \% labeling index in PBS control was $68 \%$ with a maximum variation of $\pm 2 \%$ between samples. The data are expressed as relative labeling index. To determine the time required for the hydroxyurea-arrested cells to complete their entry into $S$ phase after serum stimulation, $\left[{ }^{3} \mathrm{H}\right]$ thymidine $(1 \mu \mathrm{Ci} / \mathrm{ml})$ was added at zero time to separate dishes containing complete medium with $10 \%$ serum only; at times specified, the cells were fixed for autoradiography, and the data are expressed as \% labeling index $(0--O)$.

stored' cells (i.e., quiescent cells preincubated with UDP-GlcNAc, see ref. [5]). As expected, the active factor delayed the onset of DNA synthesis when compared with the restored cell extract; previous experiments have shown that extracts from UDPGlcNAc-treated cells did not inhibit DNA synthesis [4]. It is noteworthy that by the end of $13 \mathrm{~h}$ about $80 \%$ of the nuclei were labeled in both experiments indicating that eventually most of the cells are able to traverse G1 whether or not active FGRF was present.

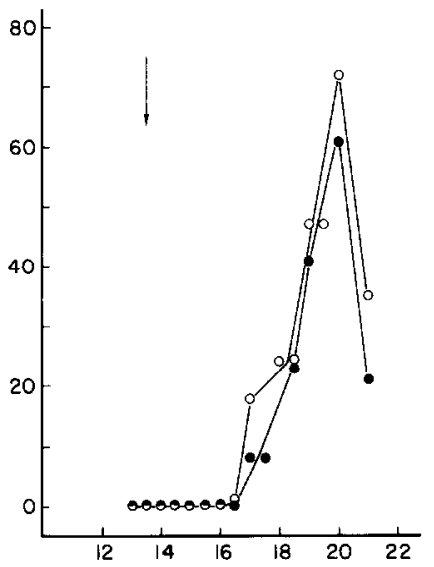

Fig. 4. Abscissa: time (hours); ordinate: mitotic nuclei/ 1000 cells.

Kinetics of entry of cells into mitosis with (-) or without (O-O) FGKF $(60 \mu \mathrm{g}$ protein/ml). Quiescent cells were obtained by seeding $2 \times 10^{6}$ cells $/ 150$ $\mathrm{mm}$ dish (containing coverslips) in $2 \%$ serum, incubating them for $48 \mathrm{~h}$ and then for an additional $12 \mathrm{~h}$ period in serum-free medium containing crystalline bovine serum albumin $(250 \mu \mathrm{g} / \mathrm{ml})$. At zero time, the medium was replaced with complete medium containing $10 \%$ serum; at $13.5 \mathrm{~h}$, as indicated by the arrow, extract was added to one dish and PBS to a control culture. At times specified cells were stained with Giemsa and the number of mitotic nuclei/ 1000 cells was scored. To estimate the time of maximum rate of DNA synthesis after serum stimulation, cells grown in separate $60 \mathrm{~mm}$ dishes were pulsed for $1 \mathrm{~h}$ with $\left[{ }^{3} \mathrm{H}\right]$ thymidine $(1 \mu \mathrm{Ci} / \mathrm{ml})$ and acid-precipitable radioactivity was determined [4]. Maximum rate of DNA synthesis $(16500 \mathrm{cpm} / \mathrm{plate})$ was between 13 and $14 \mathrm{~h}$ after serum stimulation.

\section{Effect of FGRF on $S$ phase cells}

It is well-established that growing cells can be arrested in early $S$ phase by hydroxyurea [6]; when fresh serum is added after removing hydroxyurea, these cells reinitiate DNA synthesis rapidly. In several experiments $3 T 3$ cells blocked in the early $S$ phase showed maximum nuclei labeled in a 3-5 h period after serum stimulation.

In order to determine whether FGRF would influence the time required to complete their entry into $S$ phase when added to early $S$ phase cells, the kinetics of nuclei labeling were compared with and without FGRF in $10 \%$ serum after removing hy- 


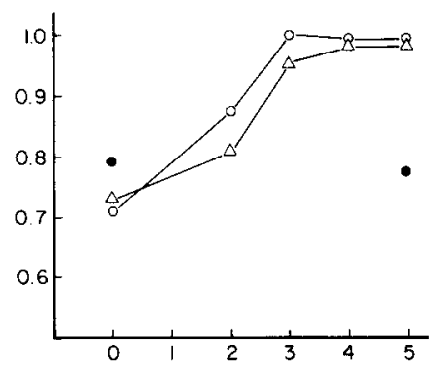

Fig. 5. Abscissa: time (hours); ordinate: rel. labeling index (see caption to fig. 3).

Extent of nuclei labcling as a function of incubation time of mitotic cells with FGRF. Mitotic cells $\left(1 \times 10^{4} /\right.$ $60 \mathrm{~mm}$ dish) were plated out in complete medium with $10 \%$ serum and $\left[{ }^{3} \mathrm{H}\right]$ thymidine $(1 \mu \mathrm{Ci} / \mathrm{ml})$. At times specified, two different preparations of FGRF $(\triangle-\triangle$; $0-0$ ) at $40 \mu \mathrm{g}$ protein $/ \mathrm{ml}$ or PBS were added to separate dishes; $20 \mathrm{~h}$ after plating of mitotic cells, coverslips were prepared for autoradiography. To monitor DNA synthesis during the second round of cell cycle, aliquots of FGRF $(40 \mu \mathrm{g}$ protein $/ \mathrm{ml})$ or PBS were added at zero time and at $5 \mathrm{~h}(\odot)$ to mitotic cells in complete medium with $10 \%$ serum; at $20 \mathrm{~h}\left[{ }^{3} \mathrm{H}\right]$ thymidine $(1 \mu \mathrm{Ci} / \mathrm{ml})$ was added to each plate and cells were fixed for autoradiography after an additional incubation period of $24 \mathrm{~h}$.

droxyurea. As shown in fig. $2 A$ the kinetics of DNA synthesis during the immediate $S$ phase in the presence or absence of the regulatory factor were identical; however, the data in fig. $2 B$ show that only a fraction of the FGRF-treated cells synthesized DNA during the following $\mathrm{S}$ phase. These results suggest that although cells exposed to FGRF during the $S$ phase were able to complete DNA synthesis, nevertheless they were prevented from entering the $S$ phase of the next round of the cell cycle.

\section{Action of FGRF on cells in $G 2$}

To obtain a population of cells in G2, cells blocked at early $\mathrm{S}$ by hydroxyurea were washed and stimulated with $10 \%$ serum, and allowed to proceed through the cell cycle. The time required for these cells to enter $S$ phase was estimated by following the kinetics of nuclei labeling after addition of $\left[{ }^{3} \mathrm{H}\right]$ thymidine to a set of dishes at the time of serum stimulation. The curve represented by the dashed line in fig. 3 shows that, in this experiment, the percentage nuclei labeled reached a maximum value at about $3 \mathrm{~h}$.

To a separate set of dishes aliquots of FGRF were added at specific time intervals after release of cells blocked by hydroxyurea. Twelve hours after serum addition, solutions of $\left[{ }^{3} \mathrm{H}\right]$ thymidine were added to all dishes and the cultures incubated for another $18 \mathrm{~h}$ prior to fixing cells for radioautography. The results of two such representative experiments are also displayed in fig. 3. It is clear that exposure of $S$ phase cells (between 0 and $3 \mathrm{~h}$ ) to FGRF resulted in a significant inhibition (20-30\%) of DNA synthesis in post-mitotic daughter cells (although, as already seen in fig. $2 A$, no inhibition was observed in the $S$ phase immediately after the addition of serum and FGRF). Interestingly, when FGRF was added to cells in late $S$ or early G2 (between 4 and $8 \mathrm{~h}$ after serum stimulation) the extent of inhibition was higher, increasing by almost 2 -fold to an average value of $50 \%$ at about 6-7 h; a small reduction in DNA synthesis was seen when FGRF was added at 9-10 and $15 \mathrm{~h}$ after release of hydroxyurea block, at which times they were presumably in G2 or G1 of the following cycle.

Control experiments, also included in fig. 3 , with inactive FGRF from restored cells showed no inhibition of DNA synthesis when added at various time periods after release of cells arrested by hydroxyurea.

The above results do not reveal whether addition of FGRF to $S$ phase cells extended G2 period as it did to G1 period when FGRF was added to G1-arrested cells (see fig. 1). To examine this, the kinetics of appearance of cells in mitosis were measured after addition of FGRF to cells during $S$ phase. For this experiment serum-arrested cells were 
Table 1. Inhibition of DNA synthesis by extracts from $3 T 3$ and $S V-3 T 3$ cells

\begin{tabular}{|c|c|c|c|c|}
\hline \multirow[b]{3}{*}{ Source of extract } & \multicolumn{4}{|c|}{ Percentages of nuclei labeled ${ }^{a}$} \\
\hline & \multicolumn{2}{|l|}{$3 \mathrm{~T} 3$} & \multicolumn{2}{|l|}{ SV-3T3 } \\
\hline & Expt 1 & Expt 2 & Expt 1 & Expt 2 \\
\hline No extract & $35(100)$ & $60(100)$ & $40(100)$ & $50(100)$ \\
\hline $3 \mathrm{~T} 3$ cells $^{b}$ & $19(54)$ & $39(65)$ & $45(113)$ & $53(106)$ \\
\hline SV-3T3 cells ${ }^{b}$ & $14(40)$ & $37(62)$ & $36(90)$ & $45(90)$ \\
\hline
\end{tabular}

${ }^{a}$ Cells $\left(2-3 \times 10^{5}\right)$ growing on $60 \mathrm{~mm}$ dishes (containing coverslips) in complete medium with $10 \%$ serum were incubated with extracts from $3 \mathrm{~T} 3$ or SV-3T3 cells $(44 \mu \mathrm{g}$ protein $/ \mathrm{ml}$ in expt 1 , and $30 \mu \mathrm{g}$ protein $/ \mathrm{ml}$ in expt 2 ) for $24 \mathrm{~h}$ at $37^{\circ} \mathrm{C}$ in a $\mathrm{CO}_{2}$ incubator and pulsed with $1 \mu \mathrm{Ci} / \mathrm{ml}$ of $\left[{ }^{3} \mathrm{H}\right]$ thymidine for $2 \mathrm{~h}$, and prepared for autoradiography. 'No extract' indicates controls with $10 \%$ serum only. The values are averages of at least 200 cells counted from two different dishes; each number in parentheses expresses the percentage of no-extract controls.

${ }^{b} 1 \times 10^{5}$ cells were seeded in $60 \mathrm{~mm}$ dishes in $4 \%$ serum and grown for $72 \mathrm{~h}$ followed by incubation for $12 \mathrm{~h}$ in serum-free medium containing $250 \mu \mathrm{g} / \mathrm{ml}$ of crystalline bovine serum albumin. Extracts were prepared as described [4]. Expts 1 and 2 indicate two separate experiments with extracts prepared from separate batches of cells on two different days.

released by addition of $10 \%$ serum and at $13.5 \mathrm{~h}$, when the cells were synthesizing DNA at maximum rate (as determined by pulsing with $\left[{ }^{3} \mathrm{H}\right]$ thymidine for $1 \mathrm{~h}$ to a separate set of dishes), FGRF was added to one set of dishes; at $0.5 \mathrm{~h}$ intervals cells were fixed and stained to determine the mitotic index. The results presented in fig. 4 show that the time of appearance of mitotic cells as well as the time required to reach the peak of mitotic index were identical in both cases indicating that cells exposed to FGRF took the same length of time to traverse the G2 period as compared to cells not treated with the extract.

\section{Response of mitotic cells to FGRF}

The cumulative results presented thus far suggest that FGRF blocks DNA synthesis by arresting cells in the G1 phase of the cell cycle. To locate the approximate position of the growth-arrest point in G1, mitotic cells were plated out in complete medium in $10 \%$ serum containing $\left[{ }^{3} \mathrm{H}\right]$ thymidine and aliquots of active FGRF were added to separate dishes at various times after serum addition; the extent of DNA synthesis was measured at the end of $20 \mathrm{~h}$ by autoradiography of labeled nuclei. The data presented in fig. 5 reveal significant inhibition of DNA synthesis in the next $S$ phase when FGRF was added in early G1 (i.e., up to $2 \mathrm{~h}$ after plating of the mitotic cells); addition of FGRF beyond the $2 \mathrm{~h}$ time point, however, had very little effect on DNA synthesis. A control experiment showed that significant inhibition of DNA synthesis was seen in post-mitotic daughter cells whether FGRF was added at zero $\mathrm{h}$ or at $5 \mathrm{~h}$ (fig. 5 , solid circles). A separate experiment (not shown) revealed that, in the absence of FGRF, the time required for the onset of DNA synthesis by mitotic cells plated in $10 \%$ serum was approx. $9 \mathrm{~h}$. We interpret these results to mean that there is a unique point, approx. 2-3 h into G1 (and 6-7 h before the beginning of $S$ phase), beyond which added FGRF is not able to prevent the progression of cells into the next round of cell cycle.

DNA synthesis in SV-3T3 cells

In contrast to their normal or untransformed counterparts, cells transformed by 
tumor viruses have decreased requirement for growth factors; in some instances they also appear to have lost the normal growth controls $[1,2,7]$. In view of this, experiments were designed to examine whether (a) active FGRF from quiescent 3 T3 cells inhibits DNA synthesis in growing SV-3T3 cells, and (b) SV-3T3 cells contain the regulatory factor that influences DNA synthesis in growing $3 \mathrm{~T} 3$ cells. The results of two such experiments, summarized in table 1 , show that extracts from quiescent $3 \mathrm{~T} 3$ cells failed to inhibit DNA synthesis in growing SV-3T3 cells relative to controls with no extract, whereas the same extract reduced the labeling index by an average value of $40 \%$ in growing $3 \mathrm{~T} 3$ cells. Similar results have been reported [8] using octylglucoside extracts of plasma membrane-enriched fraction from density-inhibited Swiss 3T3 cells.

The results displayed in table 1 also show that extracts prepared from 'quiescent' SV$3 \mathrm{~T} 3$ cells (in a manner identical with that described for quiescent 313 cells) inhibited DNA synthesis in growing $3 \mathrm{~T} 3$ cells; the extent of inhibition was about the same as that seen with active FGRF from 3T3 cells. However, extracts prepared from SV-3T3 cells showed only a marginal effect on transformed cells.

\section{DISCUSSION}

Evidence in the literature suggests that of the four distinct phases of the cell cycle ( $\mathrm{G} 1, \mathrm{~S}, \mathrm{G} 2$ and $\mathrm{M}$ ), the $\mathrm{G} 1$ period is a major site for control of proliferation of animal cells. For example, when cells are seeded in sparse culture in low serum concentration, or allowed to grow in high serum concentration to density-inhibited state, they become arrested in the G0/G1 stage of the cell cycle [1-3]. Nutritional manipulation such as amino acid starvation also leads to cells' arrest in G1 [9]. Inhibition of cell division by interferon in mouse cell lines and a human strain has also been correlated with the delayed entry of G0/G1 cells into the $S$ phase [10], although some extension of $\mathrm{S}+\mathrm{G} 2$ period is also seen [11]. A series of kinetic experiments on the cells' re-entry from quiescence to $S$ phase under a variety of conditions has led to the proposal of a restriction-point control in G1 [12]; sequential addition of platelet-derived growth factor and platelet-poor plasma reveal additional growth-arrest points in the Gl stage of the cell cycle [13].

The experiments described here were designed to analyse the physiological effect of FGRF in the cell cycle. The results show that addition of FGRF to a synchronized population of BALB/c $3 \mathrm{~T} 3$ cells in late $\mathrm{G} 1$ or early $S$ did not influence DNA synthesis during the immediate $S$ phase. However, a significant decrease in DNA synthesis was observed in post-mitotic daughter cells. FGRF added to late S/early G2 cells or cells entering G1 after mitosis showed inhibition of DNA synthesis during the upcoming $S$ phase. Further, addition of increasing concentrations of FGRF in the presence of $10 \%$ serum to cells arrested in G1 by serum limitation progressively delayed their entry into the $S$ phase, although eventually they were able to traverse the G1. These results suggest that FGRF blocks DNA synthesis and cell division by arresting cells in G1, thus preventing their entry into a new round of cell cycle (fig. 6).

The precise location of the FGRF-mediated growth-arrest point in G1 is uncertain. The results shown in fig. 5 suggest that it may be located somewhere in early G1, since addition of FGRF at $3 \mathrm{~h}$ after plating of mitotic cells allowed them to escape the growth-arrest point and synthesize DNA in 


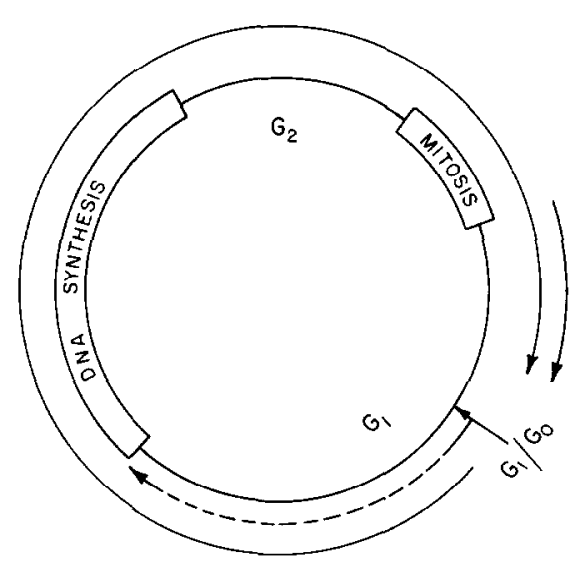

Fig. 6. Schematic representation of the action of FGRF in the cell cycle. Addition of FGRF at any point during late $\mathrm{G} 1, \mathrm{~S}$, or $\mathrm{G} 2$ arrests cells in early G1 of the next cycle. FGRF added to cells at early $\mathrm{G} 1$ blocks progression of cells in the same cycle. When added to serum-depleted G0/G1 cells, FGRF delays their entry into the $S$ phase (---) but eventually they are able to traverse G1. FGRF-mediated growth-arrest point may or may not be identical with the $\mathrm{G} 0 / \mathrm{G} 1$ arrest point.

a manner identical to that seen with the untreated cells. Although it is possible to argue that lack of inhibition of DNA synthesis may be due to the limited exposure of late G1 cells to FGRF, however, this appears unlikely because a slightly longer exposure time of $1-2 \mathrm{~h}$ (cf fig. 5) was sufficient to cause inhibition. Further, examination under a microscope revealed no difference in the attachment or flattening of mitotic cells treated with or without FGRF. The extension of Gl period of cells arrested by serum limitation in the presence of FGRF (see fig. 1) is also consistent with the notion that FGRF-mediated growth-arrest point is in early $\mathrm{Gl}$; whether or not it is identical to the $\mathrm{G} 0 / \mathrm{G} 1$ point remains to be established. Because increasing concentration of FGRF progressively extends the G1 pcriod, and also increases the inhibition of DNA synthesis in non-synchronous cell population (cf ref. 4), it is reasonable to propose that the cell cycle may be under posi- tive regulatory control by serum factors and negative control by FGRF, and the overall effect is determined by the relative concentrations of these components.

An important question in regard to the physiological effect of FGRF is where and how in the cell cycle does it interact leading to the cells' arrest in G1? The results obtained thus far show that FGRF added to cells in $\mathrm{Gl}$ and $\mathrm{S}$ inhibits DNA synthesis significantly (between 25 and $30 \%$ ) as compared with untreated controls. However, addition of FGRF to late S/early G2 cells shows a greater extent of inhibition in the following $S$ phase. One plausible explanation of this result is that alterations in the membrane environment as the cells begin to round up for mitosis may allow a more efficient interaction of FGRF with the cell surface.

It has been reported [14] that plasma membrane-enriched fraction from SV-3T3 cells had a marginal inhibitory effect on DNA synthesis in sparse $3 \mathrm{~T} 3$ cells and no effect on SV-3T3 cells. In our experiments FGRF isolated from SV-3T3 cells inhibited DNA synthesis in $3 \mathrm{~T} 3$ cells; at comparable protein concentration, inhibition was similar to that seen with FGRF from quiescent $3 \mathrm{~T} 3$ cells. This apparent discrepancy may be due to different growth conditions of the transformed cell lines. For isolation of FGRF from SV-3T3, $1 \times 10^{5}$ cells were seeded in $4 \%$ serum and grown for $72 \mathrm{~h}$ followed by incubation for $12 \mathrm{~h}$ in serum-free medium containing crystalline bovine serum albumin; under these conditions growth of cells was significantly reduced approaching 'quiescence'. Whittenberger \& Glaser [14], on the other hand, grew SV$3 \mathrm{~T} 3$ cclls to multilayer density in complete medium with $10 \%$ serum; presumably, these cells were still growing at a significant rate. It should be recalled in this con- 
text that FGRF isolated from growing cells did not inhibit DNA synthesis [4].

The reason why active FGRF isolated from untransformed or transformed cells does not inhibit DNA synthesis in SV-3T3 cells is not clear. Pardee [12] has proposed that the distinctive properties of the transformed cells may reflect the loss of 'restriction-point' (R-point) control which is a switching point in $\mathrm{G} 1$ that regulates re-entry of normal cells into a new round of cell cycle. Although the evidence presented here suggests that the FGRF-sensitive growtharrest point also lies in $\mathrm{G} 1$, it is possible, but not proved, that the action of FGRF may require a functional restriction-point in G1. Alternatively, it is equally possible to envisage that the transformed cells lack a separate component which is required for the expression of the inhibitory effect of FGRF.

This work was supported by the Geraldine F. Masters Cancer Research Fund and the funds from the University of Michigan Medical School.

\section{REFERENCES}

1. Holley, R W, Nature 258 (1975) 487.

2. Pardee, A B, Dubrow, R, Hamlin, J L \& Kletzien, R F, Ann rev biochem 47 (1978) 715.

3. Rudland, P S \& Jiminez de Asua, L, Biochim biophys acta 560 (1979) 91 .

4. Natraj, C V \& Datta, P, Proc natl acad sci US 75 (1978) 6115.

5. - Ibid (1978) 3859.

6. Tobey, R A \& Crissman, H A, Exp cell res 75 (1972) 460.

7. Scher, C D, Pledger, W J, Martin, P, Antoniades, H N \& Stiles, C D, J cell physiol 97 (1978) 371.

8. Whittenberger, B, Raben, D, Lieberman, M A \& Glaser, L, Proc natl acad sci US 75 (1978) 5457.

9. Tobey, R A, Methods in cell biology (ed D M Prescott) vol. 6, p. 67. Academic Press, New York (1973).

10. Sokawa, Y, Watanabe, Y, Watanabe, Y \& Kawade, Y, Nature 268 (1977) 236

11. Balkwill, F \& Taylor-Papadimitriou, J, Nature 274 (1978) 798

12. Pardee, A B, Proc natl acad sci US 71 (1974) 1286.

13. Pledger, W J, Stiles, C D, Antoniades, H N \& Scher, C D, Proc natl acad sci US 75 (1978) 2839.

14. Whittenberger, B \& Glaser, L, Proc natl acad sci US 74 (1977) 2251 .

Received June 29, 1979

Revised version received August 24, 1979

Accepted September 5, 1979 